\title{
Electrical properties of (11-22) Si:AlGaN layers at high Al contents grown by metal-organic vapor phase epitaxy
}

Humberto M. Foronda ${ }^{1,2, *}$, Daniel A. Hunter ${ }^{3}$, Mike Pietsch $^{2}$, Luca Sulmoni ${ }^{1}$, Anton Muhin ${ }^{1}$, Sarina Graupeter ${ }^{1}$, Norman Susilo ${ }^{1}$, Marcel Schilling ${ }^{1}$, Johannes Enslin ${ }^{1}$, Klaus Irmscher ${ }^{2}$, Robert W. Martin ${ }^{3}$, Tim Wernicke ${ }^{1}$, Michael Kneissl ${ }^{1}$

${ }^{1}$ Technische Universität Berlin, Institute of Solid State Physics, 10623 Berlin, Germany

${ }^{2}$ Leibniz-Institut für Kristallzüchtung, 12489 Berlin, Germany

${ }^{3}$ University of Strathclyde, SUPA, Department of Physics, Glasgow, G4 ONG, United Kingdom

*foronda@physik.tu-berlin.de

\begin{abstract}
In this work, the growth and conductivity of semipolar $\mathrm{Al}_{\mathrm{x}} \mathrm{Ga}_{1-\mathrm{x}} \mathrm{N}: \mathrm{Si}$ with $(11-22)$ orientation is investigated. $\mathrm{Al}_{\mathrm{x}} \mathrm{Ga}_{1-\mathrm{x}} \mathrm{N}: \mathrm{Si}(\mathrm{x}=0.60 \pm 0.03$ and $\mathrm{x}=0.80 \pm 0.02)$ layers were grown with different $\mathrm{SiH}_{4}$ partial pressures and the electrical properties were determined using Hall measurements at room temperature. The aluminum mole fraction was measured by wavelength dispersive X-ray spectroscopy and X-ray diffraction and the Si-concentration was measured by wavelength dispersive X-ray spectroscopy and secondary ion mass spectroscopy. Layer resistivities as low as $0.024 \Omega \mathrm{cm}$ for $\mathrm{x}=0.6$ and $0.042 \Omega \mathrm{cm}$ for $\mathrm{x}=0.8$ were achieved. For both aluminum mole fractions the resistivity exhibits a minimum with increasing $\mathrm{Si}$ concentration which can be explained by compensation due to formation of cation vacancy complexes at high doping levels. The onset of self-compensation occurs at larger estimated Si concentrations for larger Al contents.
\end{abstract}


The efficiency of UVC-LEDs emitting below $240 \mathrm{~nm}$ drops strongly with decreasing emission wavelength $[1,2]$. One of the reasons is that LEDs grown on c-plane sapphire suffer from a change in the optical polarization from dominant transverse electric (TE) polarized emission to dominant transverse magnetic (TM) polarized emission at $240 \mathrm{~nm} \mathrm{[3,} \mathrm{4],} \mathrm{which}$ subsequently leads to a reduced light extraction efficiency (LEE) [5-7]. However, UVC-LEDs on semipolar planes, i.e. (11-22), overcome poor LEE through a rotation of the wurtzite unit cell [8]. Furthermore, semipolar MQWs exhibit reduced internal polarization fields, which leads to a high electron and hole wave function overlap and high radiative recombination rate $[6,9,10]$. The (11-22) orientation can be nucleated on (10-10) m-plane sapphire [11], and has shown success in InGaN devices $[12,13]$. However, there has only been one report of a UV LED consisting of (11-22) AlGaN layers, emitting at $307 \mathrm{~nm}$ [14]

To realize an efficient semipolar UV LED, highly conductive n-doped layers are essential as current is transported laterally from the n-contacts to the pn-junction and high layer resistance leads to current crowding [15]. However, there is very little literature on Si-doping of (11-22) AlGaN layers $[16,17]$, especially at higher $\mathrm{Al}$ contents. In this work we present the growth of conductive (11-22) AlGaN:Si on (10-10) m-plane sapphire by metal organic vapor phase epitaxy (MOVPE) at an $\mathrm{Al}$ contents of $60 \%$ and $80 \%$. Such n-layers would be suitable for the realization of LEDs emitting at $270 \mathrm{~nm}$ and $240 \mathrm{~nm}$, respectively [18]. The Si-concentration and AlN mole fraction were determined by wavelength dispersive x-ray spectroscopy (WDX) and the electrical properties were determined by room temperature Hall measurements.

MOVPE growth was performed in a closed coupled showerhead reactor using trimethyaluminum (TMAl), trimethylgallium (TMGa), silane $\left(\mathrm{SiH}_{4}\right)$, and ammonia $\left(\mathrm{NH}_{3}\right)$ on 2 " 
on-axis m-plane (10-10) sapphire substrates. The sapphire substrates underwent 600 seconds of nitridation at a temperature of $1135^{\circ} \mathrm{C}$, at a rector pressure of $500 \mathrm{hPa}$, and with an $\mathrm{NH}_{3}$ partial pressure of $30 \mathrm{~Pa}$.

The growth of AlN and unintentionally doped AlGaN used in the structures was tailored to mitigate and eliminate the density of misoriented grains on the surface and are detailed elsewhere [19]. For the samples grown at 60\% Al, the TMAl/ (TMGa+TMAl) partial pressure ratio in the gas phase was 0.60 and the V/III ratio was 470 . The carrier gas flow into the reactor was 20 standard liters per minute (slm) of hydrogen at a reactor pressure of $500 \mathrm{hPa}$. The growth temperature was $1095^{\circ} \mathrm{C}$. The TMAl, TMGa, and NH3 partial pressures were $5 \mathrm{~Pa}, 3 \mathrm{~Pa}$, and $3750 \mathrm{~Pa}$, respectively. The $\mathrm{SiH} 4 / \mathrm{III}$ ratio was varied from $1.5 \times 10-5$ to $3 \times 10-4$. For the samples grown at $80 \% \mathrm{Al}$, the TMAl/ (TMGa+TMAl) partial pressure ratio in the gas phase was 0.76 . The mean growth temperature was $1100{ }^{\circ} \mathrm{C}$ and a V/III ratio of 630. The TMAl, TMGa, and NH3 partial pressures were $5 \mathrm{~Pa}, 1 \mathrm{~Pa}$, and $3750 \mathrm{~Pa}$, respectively. The SiH4/III ratio was varied from $5 \times 10-5$ to $6 \times 10-4$. The thickness of the AlGaN layers was determined using in-situ spectroscopic reflectance using a Laytec EpiCurve TT system. At $60 \%$ Al, the film thickness of the layer was on average $1.15 \mu \mathrm{m}$. At $80 \% \mathrm{Al}$, the film thickness of the layer was on average $0.55 \mu \mathrm{m}$. The (11-22) growth orientation in the AlGaN layers was confirmed by $\mathrm{x}$-ray diffraction (XRD) for each sample with an omega-two theta scan using an open detector in double axis configuration with a four-bounce monochromator in the incident beam. No additional peaks, such as the (1-10-3) AlGaN, which has been the subject of discussion in other works [20-22], were observed. A representative $\omega / 2 \theta$ scan exhibiting the sapphire (30-30) and the AlN and AlGaN (11-22) reflexes is shown in Figure 1.a.

The crystal quality was assessed by XRD open detector rocking curve scans of the 
symmetric (11-22) refection. All samples exhibited a FWHM of 1800" with incidence along the [10-10] and 900" with incidence along the [11-2-3] in-plane direction for all samples hinting to a high density of threading dislocations in the range of $10^{10}-10^{11} \mathrm{~cm}^{-2}[23,24]$. The FWHM of the omega rocking curves scans showed no dependence on the Si concentration or Al content and remained constant throughout all samples. The surface morphology and root-mean squared (RMS) roughness were investigated and determined using an atomic force microscope (AFM) in contact mode. As the silicon concentration is increased, the surface morphology and roughness remained unchanged and is shown to be independent of the increasing silicon concentration.

Fig.1b shows a representative AFM image of the surface morphology which an RMS roughness of $3.08 \mathrm{~nm}$ at a $\mathrm{SiH}_{4} / \mathrm{III}$ of $1.25 \times 10^{4}$ at an $\mathrm{Al}$ mole fraction of $60 \%$.

(a)

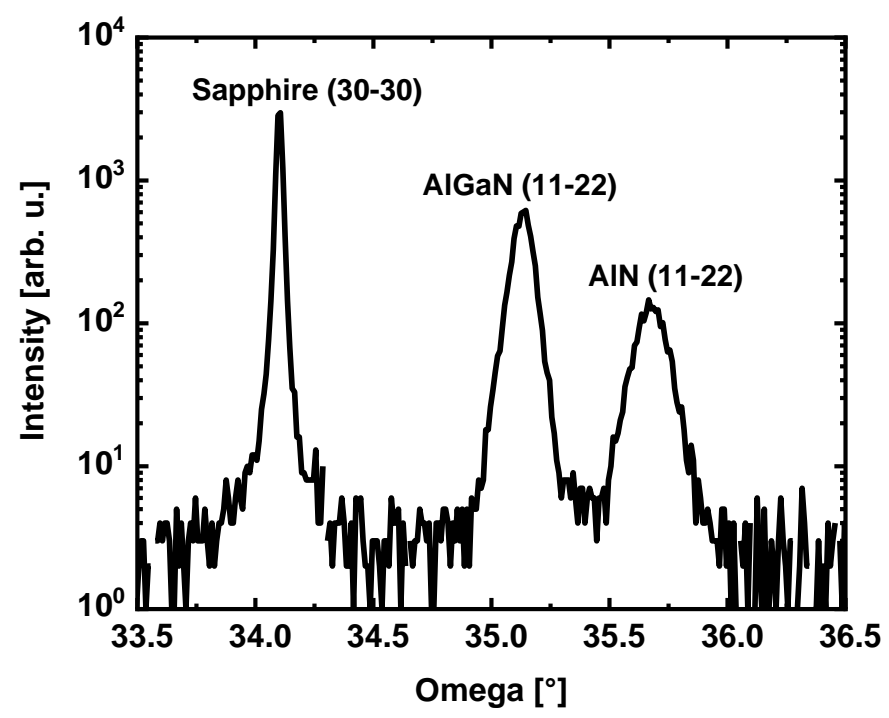

(b)

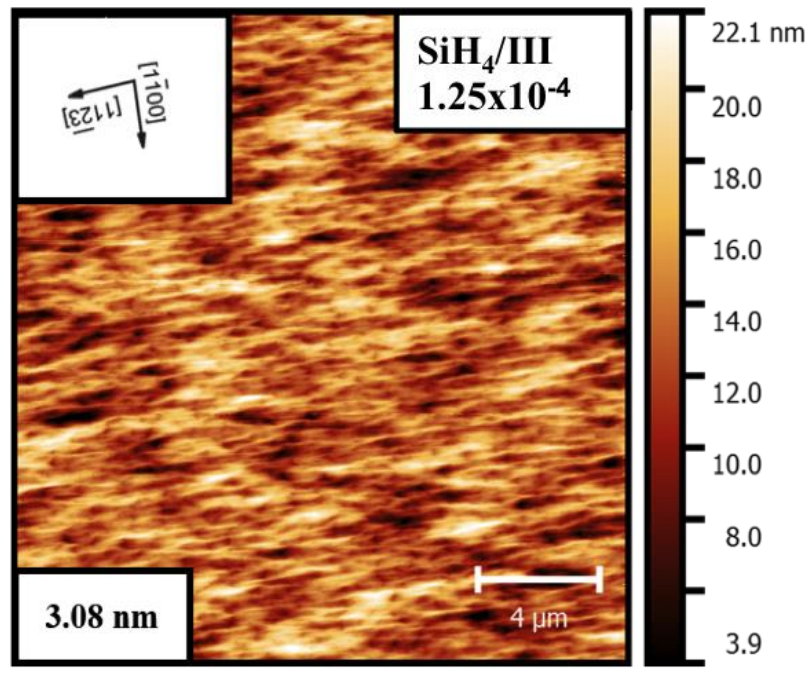

Figure 1 (a)Symmetric HR-XRD $\omega / 2 \theta$ scan of AlGaN:Si / AlN on m-plane sapphire. (b) $20 \mu \mathrm{m} \times 20 \mu \mathrm{m}$ AFM images of the $\mathrm{n}-\mathrm{AlGaN}$ surface at $\mathrm{SiH} / \mathrm{III}$ of $1.25 \times 10^{4}$ with an RMS roughness of $3.08 \mathrm{~nm}$. 
The WDX measurements in this work were performed on an electron probe microanalyser (JEOL JXA-8530F) using a $10 \mathrm{keV}$ electron beam. Monte Carlo simulations, using CASINO software [25] indicate that this beam energy corresponds to deposition of $90 \%$ of the beam energy within an approximate depth of $500 \mathrm{~nm}$ for high AlN mole fraction $\left(\mathrm{Al}_{0.7} \mathrm{Ga} 0.3 \mathrm{~N}\right)$ and 450nm for the higher density lower $\mathrm{AlN}$ mole fractions $\left(\mathrm{Al}_{0.5} \mathrm{Ga} 0.5 \mathrm{~N}\right)$.

The WDX measurements to determine the Al, Ga and $\mathrm{N}$ compositions were performed using a $40 \mathrm{nA}$ beam current and X-ray counting times of $60 \mathrm{~s}$ (for the peak) and $30 \mathrm{~s}$ (for the backgrounds). K-Ratios (X-ray intensity from sample divided by that from the standard) were determined by comparing data from the sample to a $\mathrm{AlN}$ :Si standard for the $\mathrm{Al}$ and $\mathrm{N}$ composition and $\mathrm{GaN}$ for Ga. Due to the smaller Si concentration the beam current was increased to 400nA with extended counting times (360/180s). Pure Si was used as the standard. Results from both measurements were then combined within the WDX software. A large thallium acid phthalate (TAP) crystal was used to record the $\mathrm{Al} \mathrm{K}_{\alpha}, \mathrm{Ga} \mathrm{L}_{\alpha}$ and $\mathrm{Si} \mathrm{K}_{\alpha} \mathrm{X}$-ray intensities while a layered pseudo-crystal recorded the $\mathrm{N} \mathrm{K}_{\alpha} \mathrm{X}$-ray intensity [26].

For each sample, WDX analyses were performed across 9 points corresponding to a $3 \times 3$ grid. The measured Si concentration was then calibrated using measured secondary ion mass spectroscopy (SIMS) data to provide better estimates of the dopant concentration [27,28]. Random errors were derived for each set of measurements. A systematic error of $2 \%$ was assumed for WDX measurements of $\mathrm{Al}, \mathrm{Ga}$ and $\mathrm{N}$, increasing to $3 \%$ for the more challenging measurement of Si. The AlN mole fraction of the AlGaN:Si layers was determined to be on average $60 \pm 3 \%$ and $80 \pm 2 \%$ for the samples measured by WDX.

For Hall effect measurements on $0.8 \mathrm{x} 0.8 \mathrm{~cm}^{2}$ sample pieces, V/Al/Ni/Au (15/90/20/30 $\mathrm{nm}) \mathrm{n}$-contacts were thermally evaporated, followed by a rapid annealing step of $40 \mathrm{~s}$ at $800^{\circ} \mathrm{C}$ 
under $\mathrm{N}_{2}$ atmosphere [29]. The Hall effect was measured in the van-der-Pauw configuration (Lake Shore HMS 7504) with an excitation current, magnetic field, and dwell time of $10 \mu \mathrm{A}, 3$ $\mathrm{kG}$, and $2 \mathrm{~s}$, respectively. The resistivity was additionally determined by contactless eddy current resistivity measurements (CRM).

Figure 2.a displays the silicon and carrier concentration (at $300 \mathrm{~K}$ ) as function of the $\mathrm{SiH}_{4} / \mathrm{III}$ ratio. The open red and blue points represent the $\mathrm{Si}$ concentration as measured by WDX and SIMS in the AlGaN:Si layers at 60\% $\mathrm{Al}$ and $80 \% \mathrm{Al}$, respectively. The measurements show a linear increase of the Si with the $\mathrm{SiH}_{4}$ partial pressure in the range of $2.6 \times 10^{18} \mathrm{~cm}^{-3}$ for the lowest $\mathrm{SiH}_{4} / \mathrm{III}$ ratio to $2 \times 10^{19} \mathrm{~cm}^{-3}$ for the highest $\mathrm{SiH}_{4} / \mathrm{III}$ ratio of $6 \times 10^{-4}$.

In order to later analyze the electrical properties with respect to the Si concentration in the layers, the linear regression model was applied to Si concentration measured by WDX in the AlGaN:Si layers at $60 \% \mathrm{Al}$ and $80 \% \mathrm{Al}$, where the sample grown at a $\mathrm{SiH}_{4} / \mathrm{III}$ ratio of $6 \times 10^{-4}$ was excluded for the sake of accuracy. For both aluminum mole fractions the Si incorporation is identical within the scattering of the measured data points. This is consistent with a linear $\mathrm{Si}$ incorporation independent of the aluminum mole fraction observed for c-plane $\mathrm{Al}_{\mathrm{x}} \mathrm{Ga}_{1-\mathrm{x}} \mathrm{N}$ [26]. The y intercept ( $\mathrm{Si}$ concentration) was set to 0 , with the assumption that at a $\mathrm{SiH}_{4} / \mathrm{III}$ ratio of 0 , the $\mathrm{Si}$ concentration is also 0 and is shown graphically in Fig $2 . b$

The closed red and blue points represent the carrier concentration as determined by room temperature (RT) Hall effect measurements in the AlGaN:Si layers at an aluminum mole fraction of $60 \%$ and $80 \%$, respectively. At an aluminum mole fraction of $60 \%$, the RT carrier concentration is initially in agreement with the Si-concentration measured by WDX, and both are increasing with increasing $\mathrm{SiH}_{4} / \mathrm{III}$ ratio, reaching a maximum at a $\mathrm{SiH}_{4} / \mathrm{III}$ ratio of $1.25 \times 10^{-4}$. After this maximum, the carrier concentration drops sharply while the Si concentration continues 
to increase. In this regime, the RT carrier density is less than one fifth of Si concentration or less, suggesting a high degree of compensation at the higher donor concentrations investigated. For the samples with an aluminum mole fraction of $80 \%$, the RT carrier concentration first increases, reaches a maximum at a $\mathrm{SiH}_{4} / \mathrm{III}$ ratio $\left(2.25 \times 10^{-4}\right)$, and then drops off, while the $\mathrm{Si}$ concentration continued to increase. The maximum appears at higher $\mathrm{SiH}_{4} / \mathrm{III}$ ratio (and $\mathrm{Si}$ concentration) compared to the samples with an aluminum mole fraction of $60 \%$. The carrier density is also significantly below the Si-concentration measured by WDX, which can be caused by a higher ionization energy of the donors [30] and a higher degree of compensation in the samples. Nonetheless, both the $\mathrm{Si}$ and carrier concentrations are increasing with increasing $\mathrm{SiH}_{4} / \mathrm{III}$ ratio. A closer look at the measured carrier density $\left(9 \times 10^{18} \mathrm{~cm}^{-3}\right)$ at the $\mathrm{SiH}_{4} / \mathrm{III}$ ratio of $1.25 \times 10^{-4}$ for an aluminum mole fraction of $60 \%$ in Fig. 2.a revealed that the carrier density is larger than the WDX measured silicon concentration ([Si] $\left.6.4 \times 10^{18} \mathrm{~cm}^{-3}\right)$. One possible explanation might be a higher donor concentration caused by unintentionally incorporated oxygen, which is known to incorporate effectively on (11-22) surfaces [31]. SIMS results obtained for this sample show an oxygen concentration of $6 \times 10^{18} \mathrm{~cm}^{-3}$, suggesting a contribution to the carrier concentration. Another explanation could be a scattering of the determined Si concentrations by WDX as this particular sample is below the linear regression. We conclude that both effects play a role showing that the calculation of the compensation ratio [32] based on SIMS, WDX and Hall effect measurements must be carefully reviewed. 
(a)

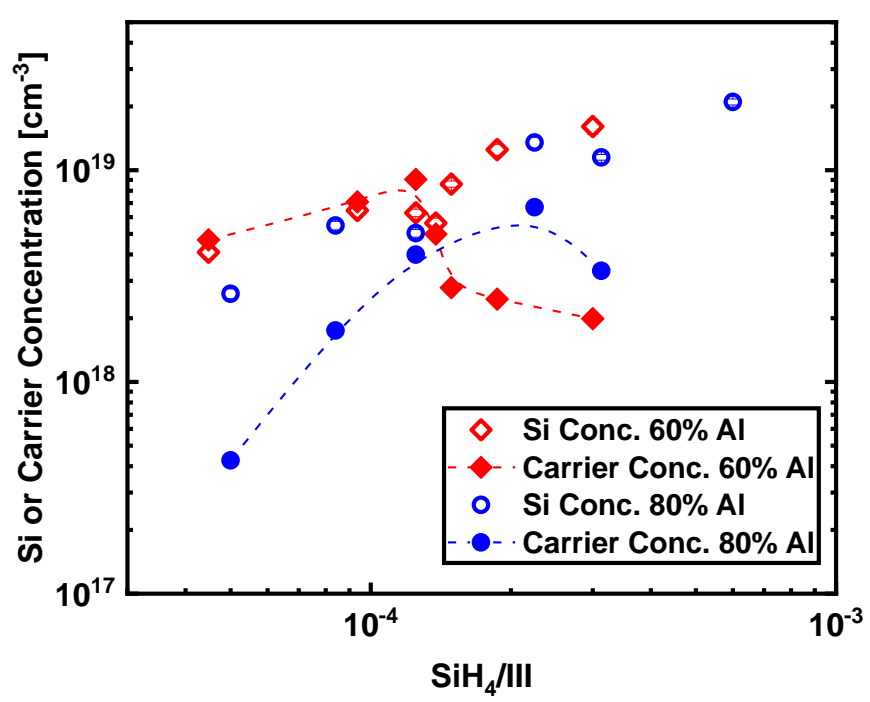

(b)

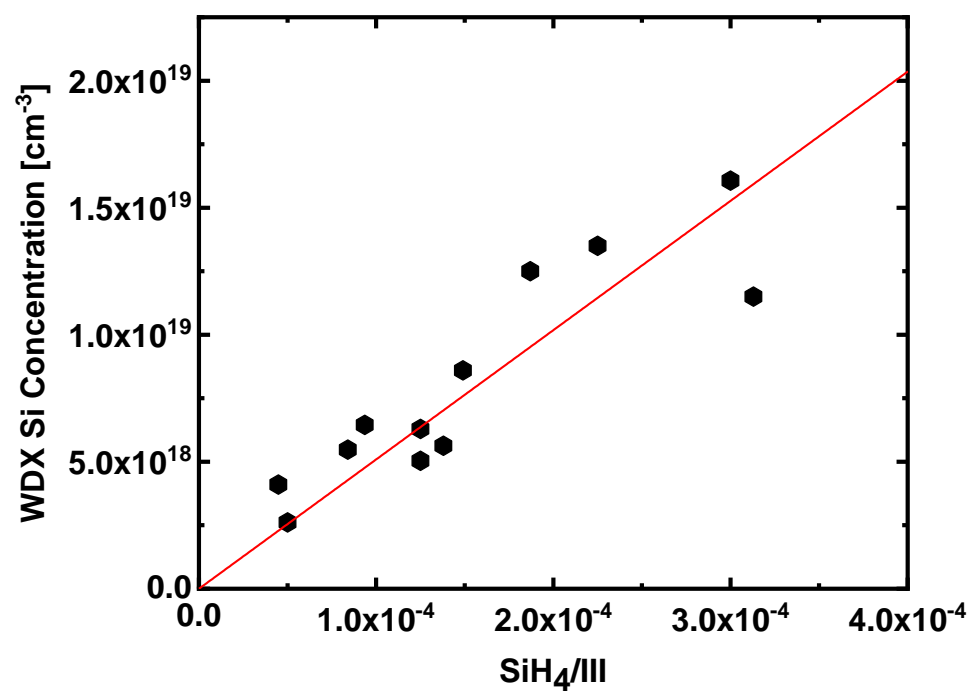

Figure 2 (a) The silicon and carrier concentration determined by WDX and Hall Effect measurement for varying $\mathrm{SiH}_{4} / \mathrm{III}$ ratio at $60 \% \mathrm{Al}$ and $80 \% \mathrm{Al}$. The carrier concentrations are marked with guides to the eye (b) Linear regression of WDX Si concentration for both Al contents as a function of $\mathrm{SiH}_{4} / \mathrm{III}$.

Figure 3 displays the results for the a. carrier concentration and b. mobility as a function of the $\mathrm{SiH}_{4} / \mathrm{III}$ ratio on the lower $\mathrm{x}$-axis and the $\mathrm{Si}$ concentration as determined by the linear regression model in the upper $\mathrm{x}$-axis. At an aluminum mole fraction of $60 \%$, an almost constant mobility and an increase in the carrier density with increasing silicon concentration was observed up to a maximum at the estimated Si concentration of $6.4 \times 10^{18} \mathrm{~cm}^{-3}\left(\mathrm{SiH}_{4} / \mathrm{III}\right.$ ratio of $\left.1.25 \times 10^{-4}\right)$. The maximum carrier density and mobility reached are $9 \times 10^{18} \mathrm{~cm}^{-3}$ and $24 \mathrm{~cm}^{2} \mathrm{~V}^{-1} \mathrm{~s}^{-1}$, respectively. Thereafter, both the mobility and carrier density decrease with increasing Si concentration. For the samples with an aluminum mole fraction of $80 \%$, an increase in both the carrier density and mobility with increasing silicon concentration is observed up to a maximum at the estimated Si concentration of $1.1 \times 10^{19} \mathrm{~cm}^{-3}\left(\mathrm{SiH}_{4} / \mathrm{III}\right.$ ratio of $\left.2.25 \times 10^{-4}\right)$. At this estimated Si concentration, the carrier density and mobility reached a maximum value of $6.7 \times 10^{18} \mathrm{~cm}^{-3}$ and 
$21 \mathrm{~cm}^{2} \mathrm{~V}^{-1} \mathrm{~s}^{-1}$, respectively. A higher Si concentration yielded a lower carrier concentration and mobility. The sample with the highest $\mathrm{SiH}_{4} / \mathrm{III}$ ratio of $6 \times 10^{-4}$ could not be measured by Hall effect measurements.

This trend is described in the literature as "knee-like behavior", being observed for AlGaN:Si with high aluminum mole fractions $[30,33,34]$. The mobility of $20-24 \mathrm{~cm}^{2} \mathrm{~V}^{-1} \mathrm{~s}^{-1}$ measured here resembles the value for high dislocation density $\left(\sim \operatorname{mid} 10^{10} \mathrm{~cm}^{-3}\right)$ c-plane Si:Alo.7Ga0.3N [33], which indicates that mobility is independent of the growth plane for materials with a high defect density, as also the samples investigated here exhibit a high dislocation density in the range of $10^{10}-10^{11} \mathrm{~cm}^{-2}[23,24]$ indicated by the FWHM of the symmetric (11-22) reflex which was equal for all samples of 900" and 1800" with incidence along [11-2-3] and [10-10], respectively.

The subsequent drop in mobility and carrier concentration is attributed to the scattering of ionized impurities along with a high dislocation density [35-37] and to the onset of selfcompensation via a cation vacancy complex with $\mathrm{Si}$, as more silane is introduced [38]. This indicates that at higher $\mathrm{SiH}_{4}$ flows, $\mathrm{Si}$ overcompensation occurs in the structures and additional Si leads to the formation of compensating defects instead of a higher net donor density. [39-41].

The "knee-like behavior" occurs at different Si concentrations for the different aluminum mole fractions reported in this work. The carrier density drops at an estimated Si concentration of $1.1 \times 10^{19} \mathrm{~cm}^{-3}$ for an aluminum mole fraction of $80 \%$, compared to an estimated $\mathrm{Si}$ concentration of $6.4 \times 10^{18}$ for an aluminum mole fraction of $60 \%$ even though the peak carrier concentration and mobility are slightly lower at an aluminum mole fraction of $80 \%\left(6.7 \times 10^{18} \mathrm{~cm}^{-}\right.$ ${ }^{3}$ and $\left.21 \mathrm{~cm}^{2} \mathrm{~V}^{-1} \mathrm{~s}^{-1}\right)$ compared to $60 \%\left(9 \times 10^{18} \mathrm{~cm}^{-3}\right.$ and $\left.24 \mathrm{~cm}^{2} \mathrm{~V}^{-1} \mathrm{~s}^{-1}\right)$. This indicates that the critical Si concentration for self-compensation, i.e., where the chemical potential of Si increases and the formation of cation vacancy complexes is favorable, depends on the $\mathrm{Al}$ content. This is 
in direct contrast to c-plane $\mathrm{AlGaN}$ with aluminum mole fraction in the range of $80 \%-96 \%$, where the critical Si concentration decreased with increasing aluminum mole fraction [30, 34], we find here the opposite trend. Further investigations will clarify if this trend can be observed as well for higher and lower aluminum mole fractions and which role oxygen plays [42], as it forms a stable DX center at aluminum mole fractions of $60 \%$ [43].

(a)

Si concentration from WDX fit $\left[\mathrm{cm}^{-3}\right]$

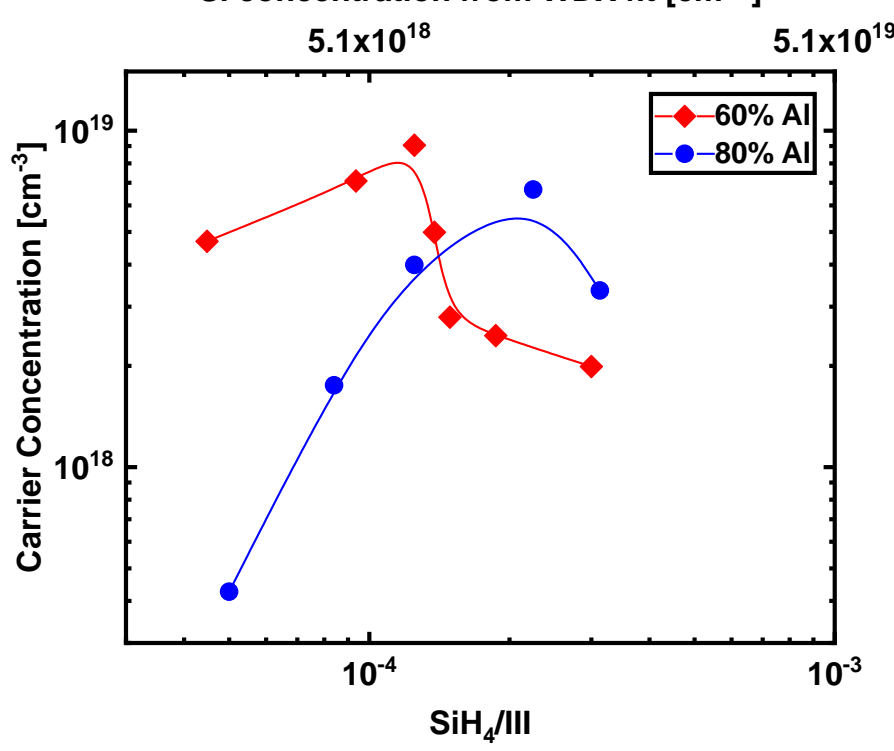

(b) Si concentration from WDX fit $\left[\mathrm{cm}^{-3}\right]$

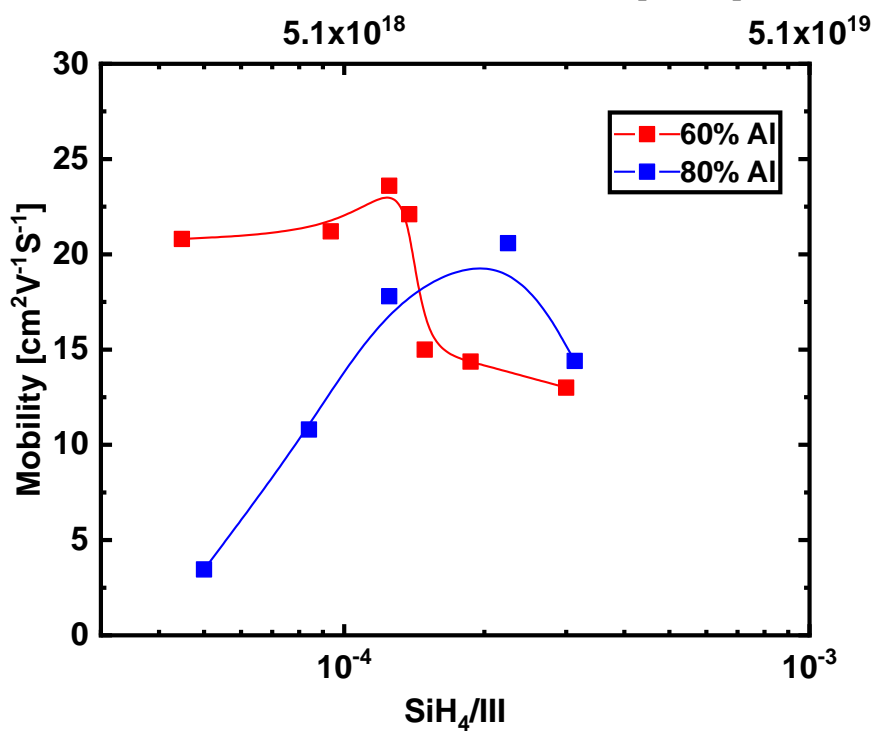

Figure 3 (a) Carrier concentration, and (b) mobility as a function of $\mathrm{SiH}_{4} / \mathrm{III}$ ratio and $\mathrm{Si}$ concentration fitted from WDX results as measured by RT Hall measurements at $60 \% \mathrm{Al}$ and $80 \% \mathrm{Al}$. The corresponding lines are simply a guide to the eye.

Figure 4 displays the layer resistivity, measured by RT Hall effect measurements and $\mathrm{CRM}$, as a function of the $\mathrm{SiH}_{4} / \mathrm{III}$ on the lower $\mathrm{x}$-axis and the Si concentration as determined by the linear regression model in the upper $\mathrm{x}$-axis. For all samples the resistivity values obtained with the two methods are in good agreement for all samples investigated. At an aluminum mole fraction of $60 \%$ (red data points) a decrease in the layer resistivity with increasing $\mathrm{Si}$ concentration was observed down to a minimum of $0.024 \Omega \mathrm{cm}$, at an estimated Si concentration of $6.4 \times 10^{18} \mathrm{~cm}^{-3}$. Thereafter, the layer resistivity increased till $\sim 0.2 \Omega \mathrm{cm}$ for the last measured 
sample at $60 \% \mathrm{Al}$ (estimated Si concentration $\sim 1.5 \times 10^{19} \mathrm{~cm}^{-3}$ ). At an aluminum mole fraction of $80 \%$, a decrease in the layer resistivity with increasing Si concentration was also observed down to a minimum of $0.042 \Omega \mathrm{cm}$, at an estimated $\mathrm{Si}$ concentration of $1.1 \times 10^{19} \mathrm{~cm}^{-3}$. The layer resistivity then increased to $\sim 1.1 \Omega \mathrm{cm}$ for the last measured sample at $80 \% \mathrm{Al}$ (estimated $\mathrm{Si}$ concentration $\sim 3 \times 10^{19} \mathrm{~cm}^{-3}$ ). For both aluminum mole fractions the lowest resistivity is caused by the highest carrier density and mobility as shown in Figure 3. Again Fig. 4 clearly demonstrates that the optimal resistivity value obtained shifts to larger estimated Si concentrations for higher $\mathrm{Al}$ contents, the opposite trend of what has observed in the literature for c-plane Al-rich

Si:AlGaN [30,34].

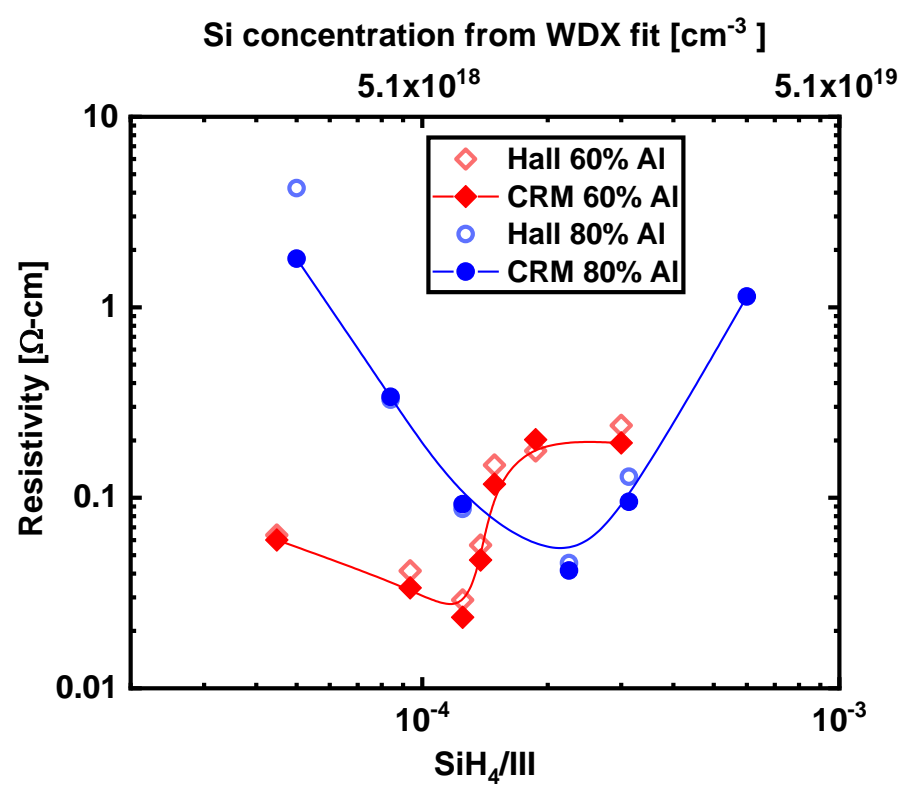

Figure 4 Layer resistivity as a function of $\mathrm{SiH}_{4} / \mathrm{III}$ ratio and $\mathrm{Si}$ concentration fitted from WDX results as measured by RT Hall measurements and contactless measurements at $60 \% \mathrm{Al}$ and $80 \%$ Al. The corresponding lines are simply a guide to the eye.

In conclusion, the growth and conductivity of (11-22) $\mathrm{Al}_{\mathrm{x}} \mathrm{Ga} 1-\mathrm{x} \mathrm{N}: \mathrm{Si}(\mathrm{x}=0.60 \pm 0.03$ and $\mathrm{x}=0.80 \pm 0.02)$ at different $\mathrm{SiH}_{4}$ partial pressures was investigated. The $\mathrm{Al}$ content and $\mathrm{Si}$ concentration were measured by WDX. The measurements show a linear increase of the $\mathrm{Si}$ 
concentration with the $\mathrm{SiH}_{4}$ partial pressure in the range of $2 \times 10^{18} \mathrm{~cm}^{-3}$ to $3 \times 10^{19} \mathrm{~cm}^{-3}$. The electrical properties were acquired using contactless resistivity measurements and Hall effect measurements at room temperature. For an aluminum mole fraction of $60 \%$ at an estimated $\mathrm{Si}$ concentration of $6.4 \times 10^{18} \mathrm{~cm}^{-3}$, a minimal layer resistivity of $0.024 \Omega \mathrm{cm}$ and maximum mobility and carrier density of $24 \mathrm{~cm}^{2} \mathrm{~V}^{-1} \mathrm{~s}^{-1}$ and $9 \times 10^{18} \mathrm{~cm}^{-3}$ were achieved, respectively. For an aluminum mole fraction of $80 \% \mathrm{Al}$, an estimated Si concentration of $1.1 \times 10^{19} \mathrm{~cm}^{-3}$, a minimal layer resistivity of $0.042 \Omega \mathrm{cm}$ and maximum mobility and carrier density of $20 \mathrm{~cm}^{2} \mathrm{~V}^{-1} \mathrm{~s}^{-1}$ and $6.7 \times 10^{18} \mathrm{~cm}^{-3}$ were achieved, respectively. Contrary to what is observed in c-plane AlGaN:Si for higher aluminum mole fractions, the peak electrical properties are observed at larger estimated silicon concentrations for larger Al contents. Therefore, the onset of self-compensation via a cation vacancy complex Si is dependent not only on the Si concentration and dislocation density, but also the $\mathrm{Al}$ content.

\section{Acknowledgements}

The authors would like to acknowledge and thank the Alexander von Humboldt Foundation for their financial support.

\section{Data Availibilty}

The data that support the findings of this study are available from the corresponding author upon reasonable request

\section{References}

[1] M.Kneissl, J.Rass, III-Nitride Ultraviolet Emitters, Technology and Applications (Springer 2016) 
[2] Michael Kneissl, Tae-Yeon Seong, Jung Han, Hiroshi Amano, "The emergence and prospects of deep ultraviolet light emitting diode technologies",

Nature Photonics 13, 233 (2019).

[3] C.Reich, M.Guttmann, M.Feneberg, T.Wernicke, F.Mehnke, C.Kuhn, J.Rass, M.

Lapeyrade, S.Einfeldt, A.Knauer, V.Kueller, M.Weyers, R.Goldhahn, M.Kneissl, Appl.

Phys. Lett. 107, 142101 (2015)

[4] R.G. Banal, M. Funato, Y. Kawakami, Phys. Rev. B 79, 121308, 2009

[5] M. Kneissl, T. Kolbe, C. Chua, V. Kueller, N Lobo, J. Stellmach, A. Knauer, H. Rodriguez,

S. Einfeldt, Z. Yang, N. M. Johnson, M. Weyers, Semicond. Sci. Technol. 520, 014036 (2011)

[6] Y.Taniyasu, M. Kasu, Appl. Phys. Lett. 96, 221110 (2010)

[7] H.Y.Ryu, I.G. Choi, J.I. Shim, APEX 6, 062101 (2013)

[8] F. Bernardini, V. Fiorentini, D. Vanderbilt, Physical Review B 56 (1997)

R10024

[9] S.Pearton, S. Nakamura, G. Fasol, The Blue Laser Diode: The Complete Story (Springer 1997)

[10] U.T. Schwarz, M. Kneissl, Phys. Stat. Solidi (RRL) 1, A44 (2007)

[11] J.Stellmach, M.Frentrup, F.Mehnke, M. Pristovsek, T.Wernicke, M. Kneissl, J. Cryst. Growth 355, 59 (2012)

[12]Y.Zhao, J. Sonoda, C. Pan, S. Brinkley, I. Koslow, K. Fujito, H. Ohta, S. P. DenBaars, S. Nakamura. Appl. Phys. Express 3, 102101 (2010)

[13] C.Pan, S. Tanaka, F. Wu, Y.Zhao, J. S. Speck, S. Nakamura, S. P. DenBaars, D. Feezell. Appl. Phys. Express 5, 062103 (2012)

[14] K. Balakrishnan, V. Adivarahan, Q. Fareed, M. Lachab, B. Zhang, A. Khan, Jap. J. Appl. Phys. 49, 040206 (2010).

[15] M. Lapeyrade, A. Muhin, S. Einfeldt, U. Zeimer, A. Mogilatenko, M.

Weyers, and M. Kneissl, Semicond. Sci. Technol. 28, 125015 (2013) 
[16] D.V.Dinh, P.Pampili, P.J.Parbrook Journal of Crystal Growth 451, 181-187 (2016)

[17] Q.Dai, X. Zhang, J.Zhao, H.Luan, Z.Liang, Y. Cui, Materials Science in Semiconductor ProcessingVolume 58, (2017)

[18] F. Mehnke, L. Sulmoni, M. Guttmann, T. Wernicke, and M. Kneissl, Applied Physics Express, 012008 (2019)

[19] H.M Foronda, S. Graupeter, F. Mehnke, J. Enslin, T. Wernicke, M. Kneissl, Japanese Journal of Applied Physics 58, SC1026 (2019)

[20] J.Stellmach, M.Frentrup, F.Mehnke, M. Pristovsek, T.Wernicke, M. Kneissl, J. Cryst. Growth 355, 59 (2012)

[21] J. Stellmach, F Mehnke, M Frentrup, Ch Reich, J Schlegel, M Pristovsek, T Wernicke, M Kneissl, Journal of Crystal Growth 367, 42 (2013)

[22] A. Mogilatenko, H. Kirmse, J. Stellmach, M. Frentrup, F. Mehnke, T.

Wernicke, M. Kneissl, M. Weyers, J. Cryst. Growth 400, 54 (2014)

[23] A. Mogilatenko, H. Kirmse, J. Stellmach, M. Frentrup, F. Mehnke, T.

Wernicke, M. Kneissl, and M. Weyers, J. Cryst. Growth 400, 54 (2014).

[24] J. Stellmach, F. Mehnke, M. Frentrup, C. Reich, J. Schlegel, M. Pristovsek, T. Wernicke, and M. Kneissl, J. Cryst. Growth 367, 42 (2013).

[25]D. Drouin, A. R. Couture, D. Joly, X. Tastet, V. Aimez, and R. Gauvin, Scanning, vol. 29, no. 3, pp. 92-101, May 2007

[26]G. Kusch, F. Mehnke, J. Enslin, P. R Edwards, T. Wernicke, M. Kneissl, R.W Martin, Semicond. Sci. Technol., vol. 32, no. 3, p. 35020, 2017

[27]C. Trager-Cowan, A Alasmari, W Avis, Jochen Bruckbauer, PR Edwards, B Hourahine, S Kraeusel, G Kusch, R Johnston, G Naresh-Kumar, RW Martin, M Nouf-Allehiani, E Pascal, L Spasevski, D Thomson, S Vespucci, PJ Parbrook, MD Smith, J Enslin, F Mehnke, M Kneissl, C Kuhn, T Wernicke, S Hagedorn, A Knauer, V Kueller, S Walde, M Weyers, P-M Coulon, PA Shields, Y Zhang, L Jiu, Yipin Gong, RM Smith, T Wang, A Winkelmann, Photonics Res., vol. 7, no. 11, p. B73, 2019

[28] L. Spasevski, G. Kusch, P. Pampili, V. Z. Zubialevich, D.V. Dinh, J. Bruckbauer, P.R. Edwards, P.J. Parbrook, and R.W. Martin, J. Phys. D: Appl. Phys. 54 (2021) 035302

[29] Luca Sulmoni, Frank Mehnke, Anna Mogilatenko, Martin Guttmann, Tim Wernicke, and Michael Kneissl, "Electrical properties and microstructure formation of V/Al-based n-contacts on high Al mole fraction n-AlGaN layers," Photon. Res. 8, 1381-1387 (2020) 
[30] F. Mehnke, X. T. Trinh, H. Pingel, T. Wernicke, E. Janzen, N. T. Son, and M. Kneissl, J. Appl. Phys. 120, 145702 (2016).

[31] D.A. Browne, E.C. Young, J.R. Lang, C.A. Hurni, J.S. Speck, Journal of Vacuum Science \& Technology A 30, 041513 (2012)

[32] D.C. Look, Electrical Characterization of GaAs Materials and Devices, John Wiley and Sons Ltd. (1989)

[33] I. Bryan, Z. Bryan, S. Washiyama, P. Reddy,2 B. Gaddy, B. Sarkar, M.H. Breckenridge, Q. Guo, M. Bobea, J. Tweedie, S. Mita, D. Irving, R.Collazo, Z. Sitar APPLIED PHYSICS LETTERS 112, 062102 (2018)

[34] F. Mehnke, T. Wernicke, H. Pingel, C. Kuhn, C. Reich, V. Kueller, A. Knauer, M. Lapeyrade, M. Weyers, and M. Kneissl, Appl. Phys. Lett. 103, 212109 (2013).

[35] J.L. Farvacque, PHYSICAL REVIEW B, 62, 4 (2000)

[36] W.T. Read Jr. LXXXVII. Theory of dislocations in germanium, Philosophical Magazine Series 7, 45:367, 775-796, (1954)

[37] J.L. Farvacque, Z. Bougrioua, and I. Moerman, PHYSICAL REVIEW B, 63, $115202,(2001)$

[38] S. F. Chichibu, H. Miyake, Y. Ishikawa, M. Tashiro, T. Ohtomo, K. Furusawa, K. Hazu, K. Hiramatsu, and A. Uedono, J. Appl. Phys. 113, 213506 (2013).

[39] K.B. Nam, J. Li, M.L. Nakarmi, J.Y. Lin, H.X. Jiang, Appl. Phys. Lett. 81 (2002) 1038.

[40] K.X. Chen, Q. Dai, W. Lee, J.K. Kim, E.F. Schubert, W. Liu, S. Wu, X. Li, J.A. Smart, Appl. Phys. Lett. 91 (2007) 121110.

[41] A. Uedono, K. Tenjinbayashi, T. Tsutsui, Y. Shimahara, H. Miyake, K. Hiramatsu, N. Oshima, R. Suzuki, S. Ishibashi, J. Appl. Phys. 111 (2012) 013512

[42] A. Kakanakova-Georgieva,a) D. Nilsson, X. T. Trinh, U. Forsberg, N. T. Son, and E. JanzenAppl. Phys. Lett. 102, 132113 (2013);

[43] Joshua S. Harris, Benjamin E. Gaddy, Ramón Collazo, Zlatko Sitar, and Douglas L. Irving Phys. Rev. Materials 3, 054604 (2019) 
(a)

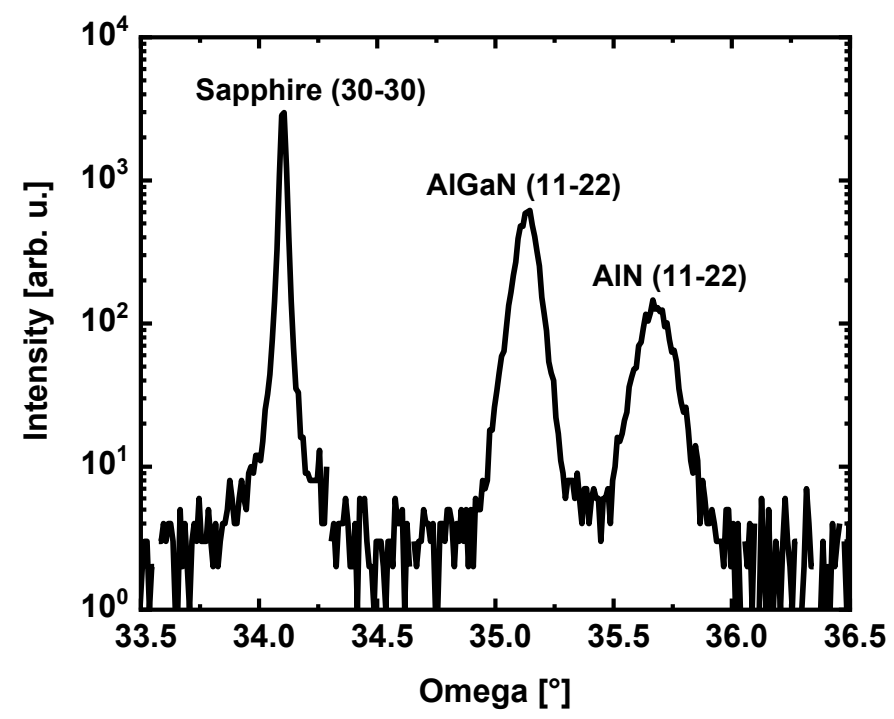

(b)

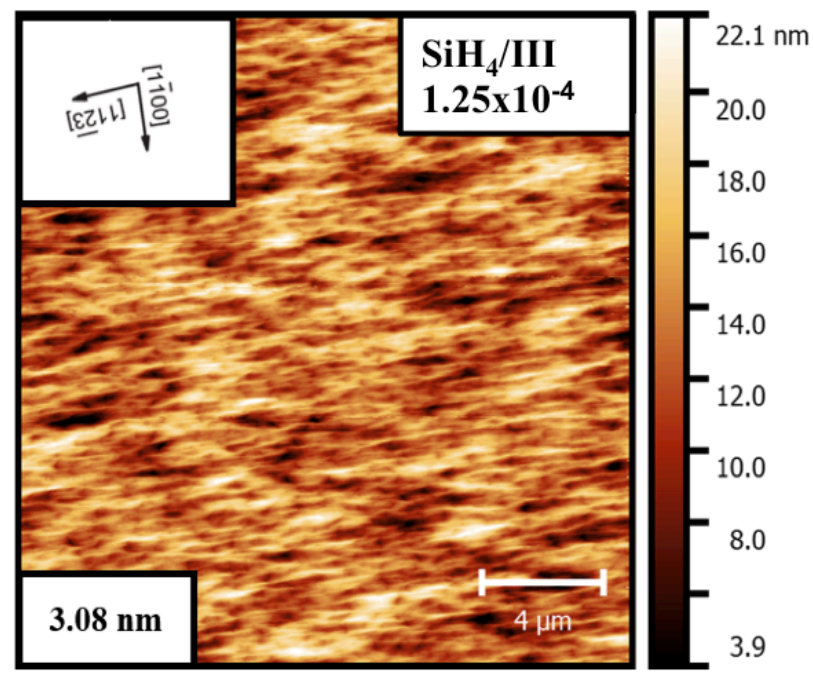


(a)

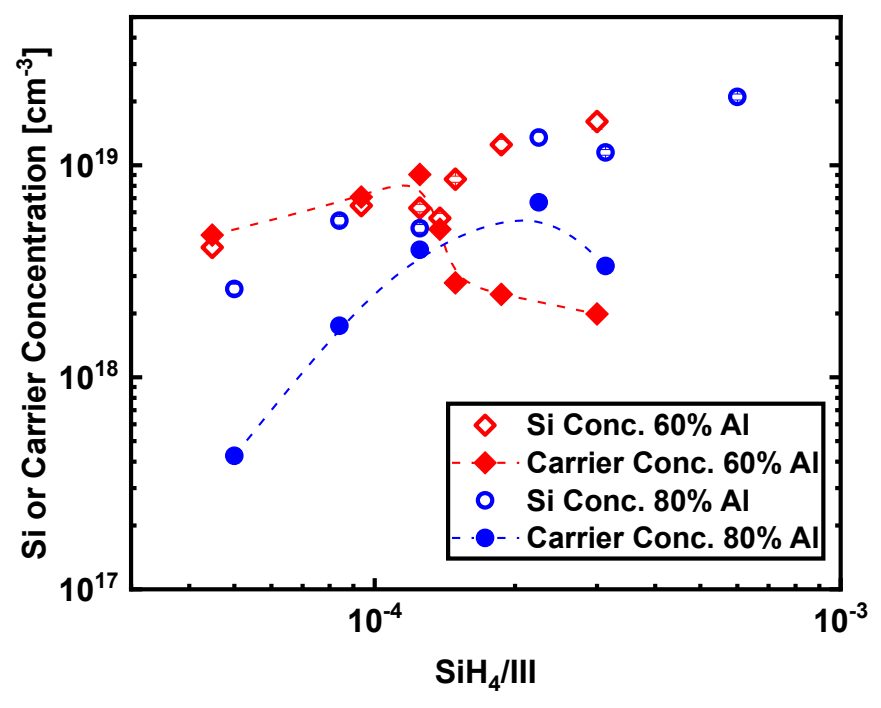

(b)

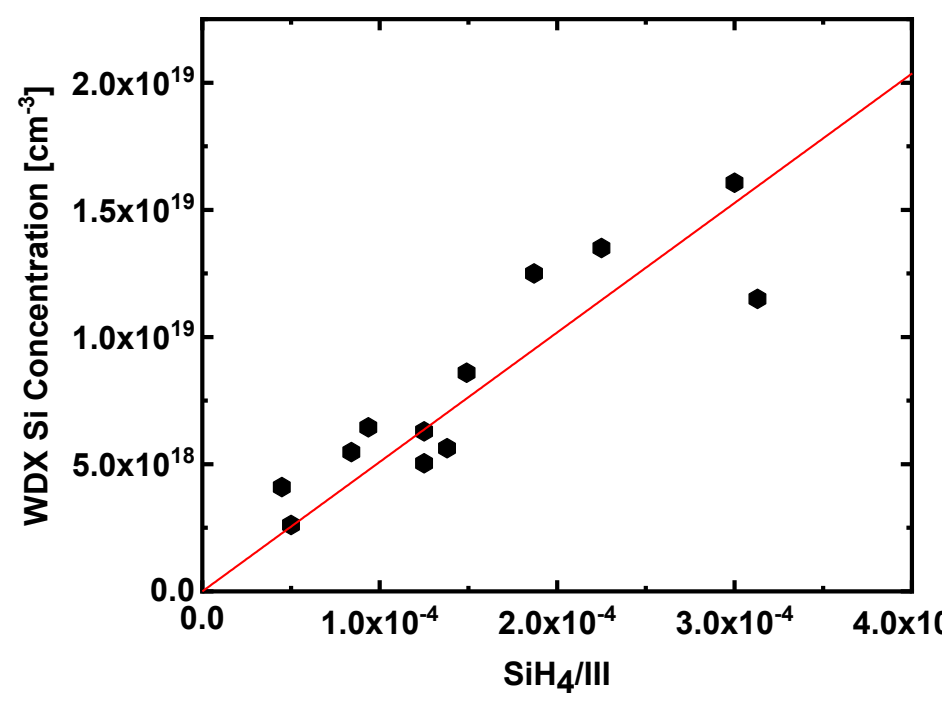


(a)

Si concentration from WDX fit $\left[\mathrm{cm}^{-3}\right]$

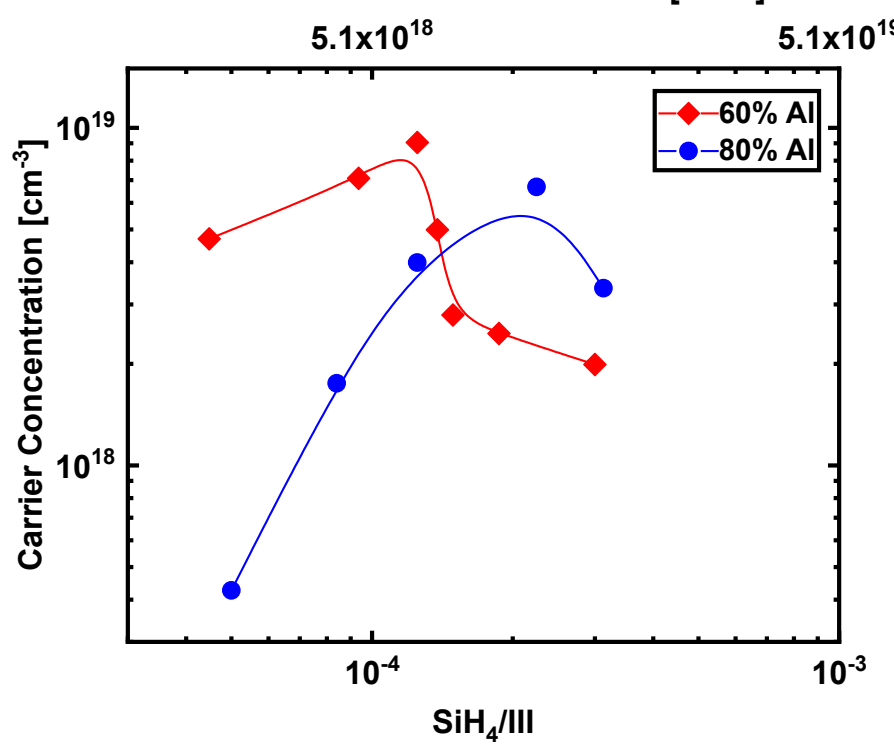

(b)

Si concentration from WDX fit $\left[\mathrm{cm}^{-3}\right]$

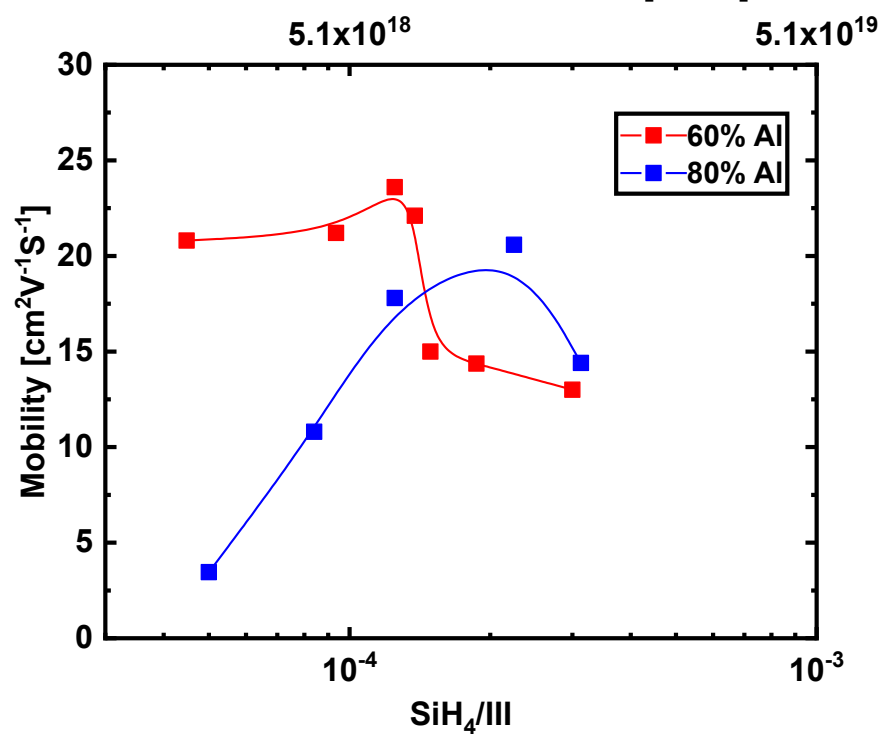




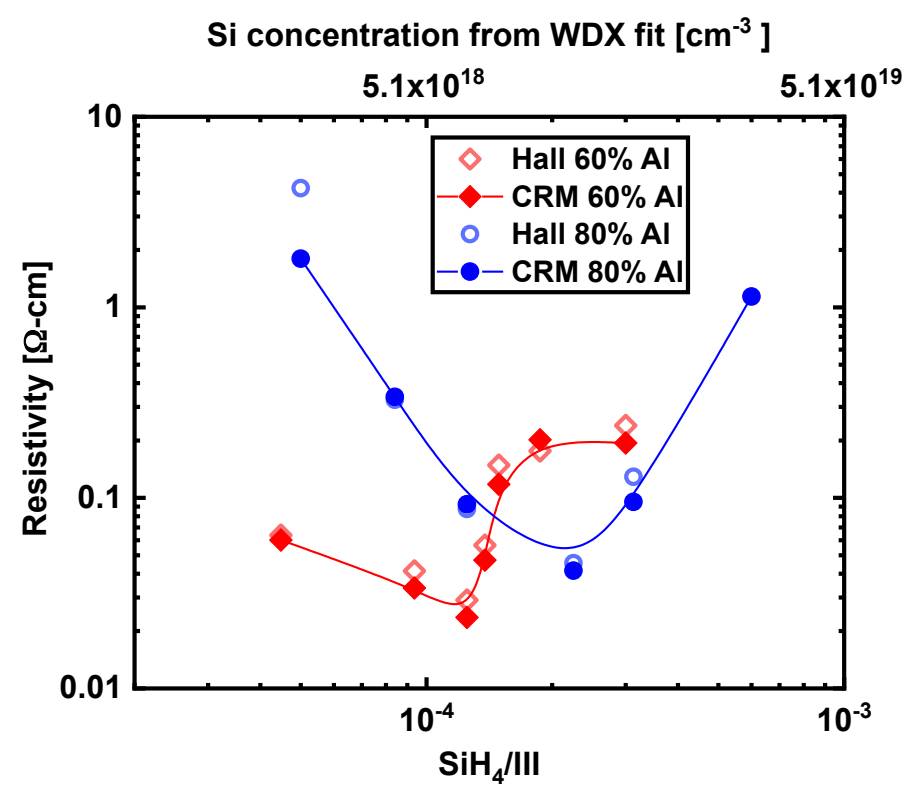

